\title{
Supplement to "Impacts of the COVID-19 lockdown on air pollution at regional and urban background sites in northern Italy."
}

Jean-Philippe Putaud' ${ }^{1}$, Luca Pozzoli', Enrico Pisoni', Sebastiao Martins Dos Santos ${ }^{1}$, Friedrich Lagler ${ }^{1}$, Guido Lanzani ${ }^{2}$, Umberto Dal Santo ${ }^{2}$, Augustin Colette ${ }^{3}$

${ }^{1}$ European Commission, Joint Research Centre (JRC), Ispra, Italy

${ }^{2}$ Agenzia Regionale per la Protezione dell'Ambiente (ARPA-Lombardia), Milan, Italy

${ }^{3}$ Institut National de I'Environnement Industriel et des Risques (INERIS), Verneuil-en-Halatte, France

1 CAMS-Ensemble forecast and observation data

This section presents CAMS-Ensemble forecast and measurement data. It deals with trends in these data, and in the agreement between these data. These trends are not used to assess the impacts of lockdown measures on air pollution, but CAMS-Ensemble forecast 2019 and 2020 data, as well as observation 2019 data were used to compute expected concentrations for 2020 (as if no lockdown had occurred).

\subsection{Nitrogen Dioxide $\left(\mathrm{NO}_{2}\right)$}

In February - May, $\mathrm{NO}_{2}$ concentrations are on average 2 to 3 times as much in Milan (about $35 \mu \mathrm{g} \mathrm{m}^{-3}$ ) as in Ispra (about 15 $\mu \mathrm{g} \mathrm{m}^{-3}$ ). CAMS-Ensemble forecast and observation data both show decreasing trends across the period 17 Feb. $-25 \mathrm{May}$ at both sites and for both 2019 and 2020 (Figure S1). The correlation between 2019 model and observation data is better in Milan ( $R^{2}=$ $0.67)$ than in Ispra $\left(R^{2}=0.58\right)$. CAMS-Ensemble forecast $2020 \mathrm{NO}_{2}$ concentrations are less than 2019 concentrations in both Milan $(-12 \%)$ and Ispra (-39\%). NB: these differences are independent from the 2020 lockdown measures, which are not included in the CAMS operational forecasting system. They can be due to different meteorological conditions in 2020 compared to 2019 , but we cannot rule out an impact of the modelling setup since TNO-MACC-III/2011 emissions were used in Feb. - May 2019, while CAMSREG-AP_v3.1/2016 were used in Feb.- May 2020. Because of the general decreasing trend in $\mathrm{NO}_{2}$ emissions across Europe, moving from 2011 to 2016 as a reference year led to an overall decrease in modelled concentrations. Observations are greater than CAMS forecasts at both sites until 9 March 2020, and get similar (Ispra) or lower (Milan) afterwards.
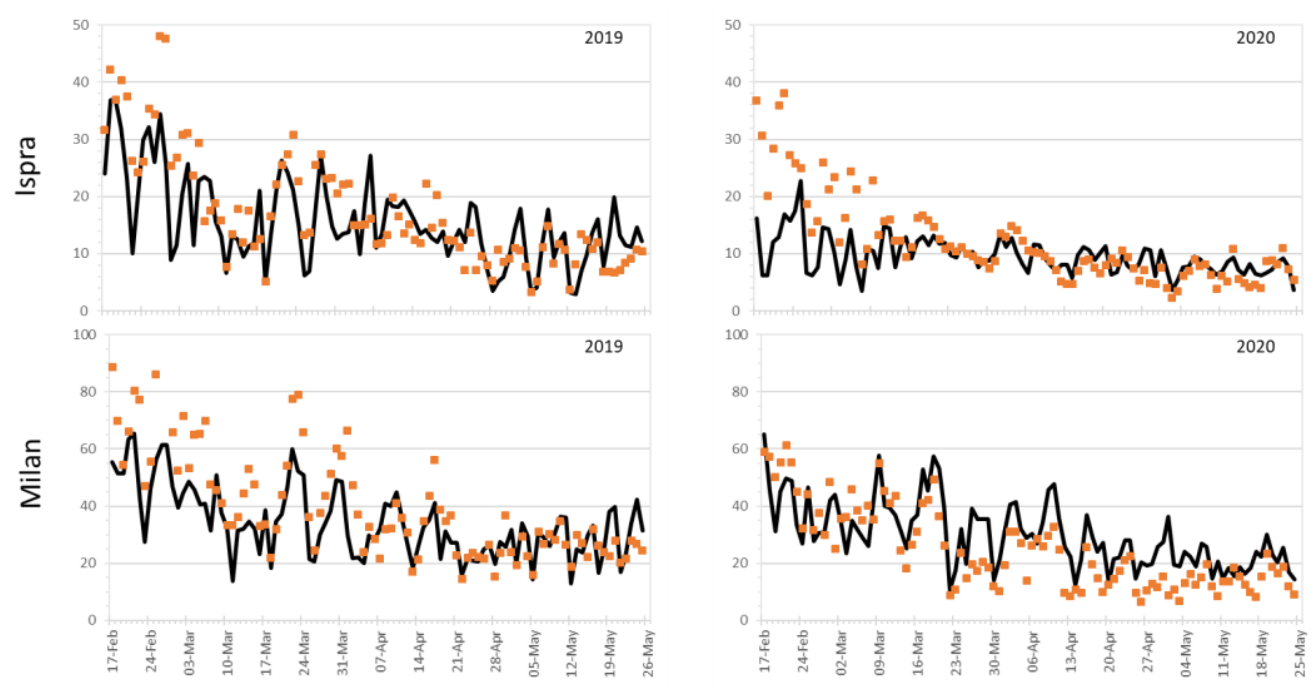

Figure S1: Observation (dots) and CAMS forecast (lines) $\mathrm{NO}_{2}$ concentrations ( $\mu \mathrm{g} \mathrm{m}^{-3}$ ) in Ispra (regional background) and Milan (urban background) for the time periods 17 Feb. - 24 May 2019 and 2020.

\subsection{Particulate Matter $\left(\mathrm{PM}_{10}\right)$}

$\mathrm{PM}_{10}$ concentrations in February - May (Figure S2) are much more similar in Milan (28 $\mu \mathrm{g} \mathrm{m}^{-3}$ ) and Ispra (about $\left.18 \mu \mathrm{g} \mathrm{m} \mathrm{m}^{-3}\right)$ than $\mathrm{NO}_{2}$ concentrations are, and correlations between $\mathrm{PM}_{10}$ concentrations at the two sites are quite good $\left(0.60<\mathrm{R}^{2}<0.73\right)$ for 
both CAMS forecast and observation data in both 2019 and 2020. PM 10 CAMS-Ensemble forecast and observation data both show decreasing trends across the period 17 Feb. - 25 May at both sites and for both 2019 and 2020 (Figure S2). The correlation between 2019 model and observation data is similar in Milan and Ispra ( $R^{2}=0.59$ and 0.64 , respectively). CAMS-Ensemble forecast $\mathrm{PM}_{10}$ concentrations are greater in 2020 than in 2019 in Milan (+20\%) and Ispra (+28\%). As for $\mathrm{NO}_{2}$, these differences could be due to different meteorological conditions in 2020 compared to 2019, and/or to the modelling setup. Again, the change from 2011 to 2016 emissions meant that a different reporting year was used. Particulate matter and particulate matter precursors' emissions have followed an overall decreasing trend in Europe for several years (EEA, 2019). However, $\mathrm{PM}_{10}$ primary emissions reported for Italy in 2016 (and used to compute 2020 concentrations) are greater than emissions reported in 2011 (and used to compute 2019 concentrations), which can be attributed to a change in emission inventory procedures (presumably related to the way condensable PM emissions were reported). Most observations are greater than CAMS forecasts at both sites until mid-March 2019, and get similar afterwards. In 2020, observations are generally greater or equal to CAMS forecasts till mid-March, and get mostly lower (Ispra) or similar (Milan) until the end of April 2020.
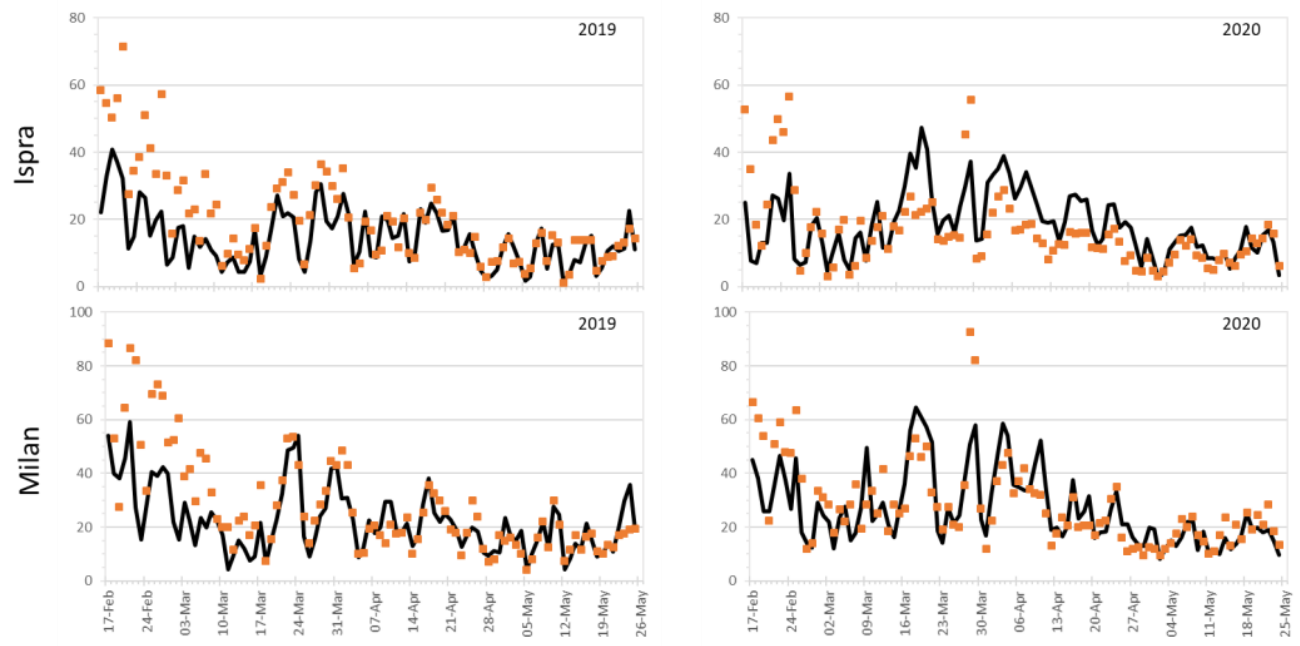

Figure S2: Observation (dots) and CAMS forecast (lines) $P M_{10}$ concentrations ( $\mu \mathrm{g} \mathrm{m}^{-3}$ ) in Ispra and Milan for the time periods 17 Feb. - 24 May 2019 and 2020.

\subsection{Nitrogen Monoxide (NO)}

NO observations were on average 15 and 8 times as much in Milan (20 and $10 \mu \mathrm{g} \mathrm{m}^{-3}$ ) as in Ispra (about $1.3 \mu \mathrm{g} \mathrm{m} \mathrm{m}^{-3}$ ) in 2019 and 2020, respectively. As for $\mathrm{NO}_{2}$ and $\mathrm{PM}_{10}$, both CAMS-Ensemble forecast and observation data generally show decreasing trends across the period 17 Feb. - 25 May at both sites and for both 2019 and 2020 (Figure S3). NO forecast by CAMS ensemble for 2020 are very low in Ispra compared to 2019 (especially for the 17 Feb. - 8 March period), while they are similar for both years in Milan. The correlation between 2019 model and observation data is better in Milan $\left(R^{2}=0.77\right)$ than in Ispra $\left(R^{2}=0.51\right)$. In both Ispra and Milan, observed NO concentrations are generally greater than CAMS forecasts till early March. They get similar to lower in Ispra, and similar to higher in Milan afterwards. 

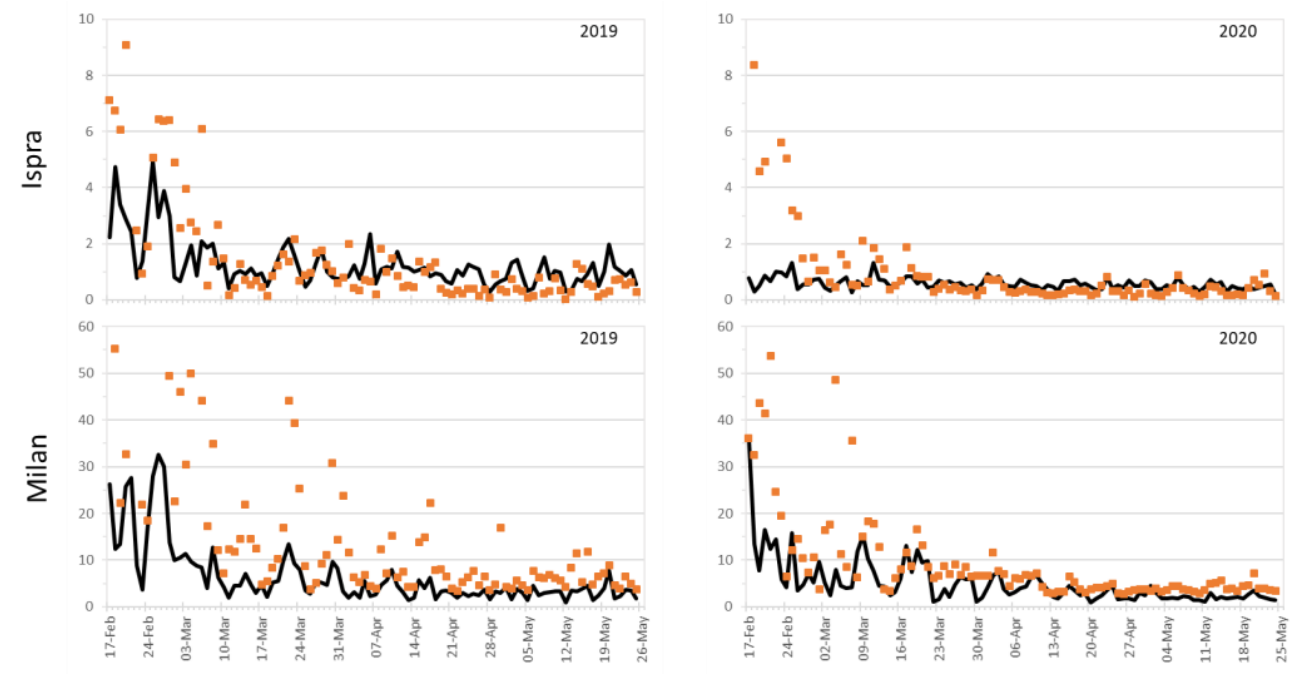

Figure S3: Observation (dots) and CAMS forecast (lines) NO concentrations ( $\left.\mu \mathrm{g} \mathrm{m}^{-3}\right)$ in Ispra and Milan for the time periods 17 Feb. - 24 May 2019 and 2020.

\subsection{Sulfur Dioxide $\left(\mathrm{SO}_{2}\right)$}

$\mathrm{SO}_{2}$ is studied in the case of Ispra only since the monitors implemented at the urban background sites in Milan did not provide data accurate enough at the concentration levels $\left(<3 \mu \mathrm{g} \mathrm{m}^{-3}\right)$ experienced in Milan during the period 17 Feb. $-24 \mathrm{May}$ 2020. In Ispra, both CAMS ensemble and observation data indicate a generally decreasing trend from 17 Feb. to 25 May 2019 (Figure S4). However, $\mathrm{SO}_{2}$ concentrations (average $=0.7 \mu \mathrm{g} \mathrm{m}^{-3}$ ) were quite variable during this period and the correlation between observations and CAMS forecasts was marginal $\left(R^{2}=0.41\right)$. In 2020 , both CAMS and observation data are about $30 \%$ less than in $2019\left(0.5 \mathrm{mg} \mathrm{m}^{-3}\right)$ and present a similar feature with 2 broad concentration "peaks" (mostly below $\left.2 \mu \mathrm{g} \mathrm{m} \mathrm{m}^{-3}\right)$ in the $3^{\text {rd }}$ week of March and the two $1^{\text {st }}$ weeks of April. In 2020, $\mathrm{SO}_{2}$ observations were generally similar to CAMS forecasts from midFebruary to mid-March and from mid-April to the end of May (Figure S4).
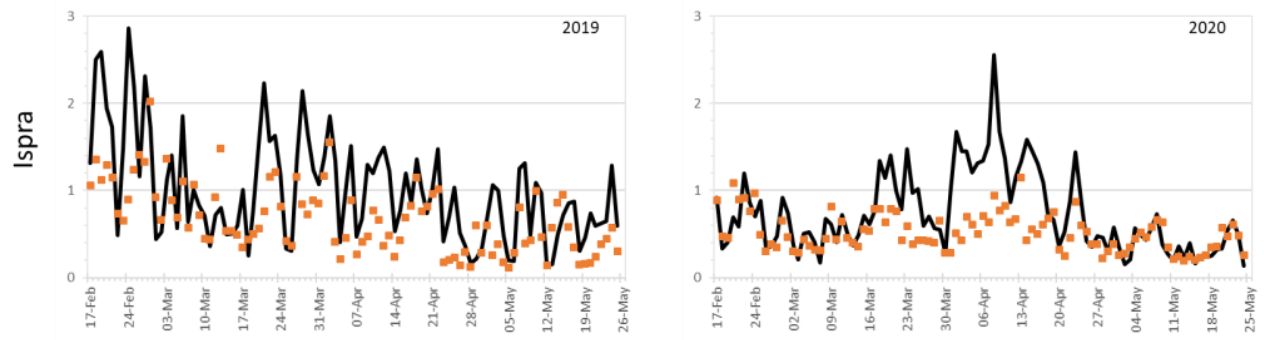

Figure S4: Observation (dots) and CAMS forecast (lines) $\mathrm{SO}_{2}$ concentrations ( $\mu \mathrm{g} \mathrm{m}^{-3}$ ) in Ispra for the time periods $17 \mathrm{Feb} .-24$ May 2019 and 2020.

\subsection{Ozone $\left(\mathrm{O}_{3}\right)$}

From February to May, $\mathrm{O}_{3}$ concentrations are similar in Ispra (about $67 \mu \mathrm{g} \mathrm{m}^{-3}$ ) and in the Milan conurbation (about $52 \mu \mathrm{g}$

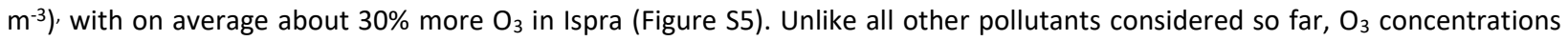
generally increase from mid-February to end of May, mainly due to increased photochemical production. CAMS Ensemble forecast predicted quite well $\mathrm{O}_{3}$ concentration variations both in Ispra and Milan for $2019\left(\mathrm{R}^{2}=0.65\right.$ and 0.70 , respectively), and only slightly overestimated $\mathrm{O}_{3}$ concentrations in Milan (+15\%). Compared to 2019, CAMS forecasts were for 2020 about $10 \%$ higher in Ispra and almost unchanged in Milan, while observed concentrations were nearly identical in Ispra, and increased by $+20 \%$ in Milan. Consequently, $\mathrm{O}_{3}$ observations are mostly less than CAMS forecasts in Ispra and generally similar to CAMS forecasts in Milan for the 17 Feb. - 25 May 2020 period. 

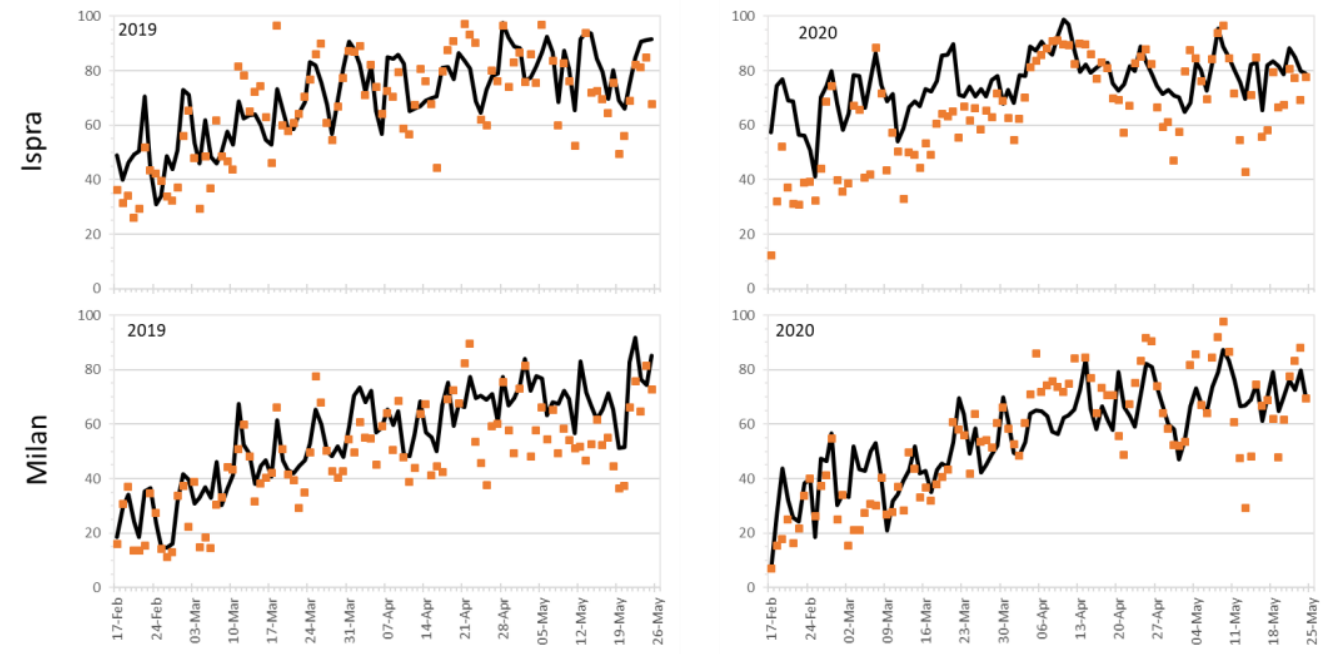

Figure S5: Observation (dots) and CAMS forecast (lines) $\mathrm{O}_{3}$ concentrations ( $\left.\mu \mathrm{g} \mathrm{m}^{-3}\right)$ in Ispra and Milan for the time periods 17 Feb. - 24 May 2019 and 2020.

\section{Aerosol intensive variables}

This section briefly describes the observation data used to compute aerosol intensive variables. Occurrence frequency distributions are also presented. They were calculated similarly to those shown in Figure 4 of the article, except that the $x$-axes represent 2020/ 2017-2019 average ratios.

The aerosol light absorption Ångström exponent (AÅE) was calculated based on hourly mean equivalent black carbon (eBC) concentrations determined at 7 wavelengths. EBC as derived from aerosol light attenuation measurements at $880 \mathrm{~nm}$ averaged $0.9 \mu \mathrm{g} \mathrm{m}^{-3}$ during the period 17 Feb. - 24 May 2020, vs. 1.2, 1.0, and $1.1 \mu \mathrm{g} \mathrm{m}^{-3}$ for the same periods in 2017, 2018 and 2019, respectively. The aerosol light absorption Ångström exponent (AÅE) jumped up on 8 March 2020 and remained mostly greater than the $2017-2019$ average till mid-May, which is illustrated by the occurrence frequency distributions (Figure S6). Compared to the $2017-2019$ average, AÅE values increased on average by almost $+7 \%$ during the lockdown period in comparison with both the 3 weeks before and the 3 weeks after the lockdown period. Figure $S 6$ also shows that days on which eBC concentrations were highest (> median) during the lockdown period were even slightly more impacted than average.

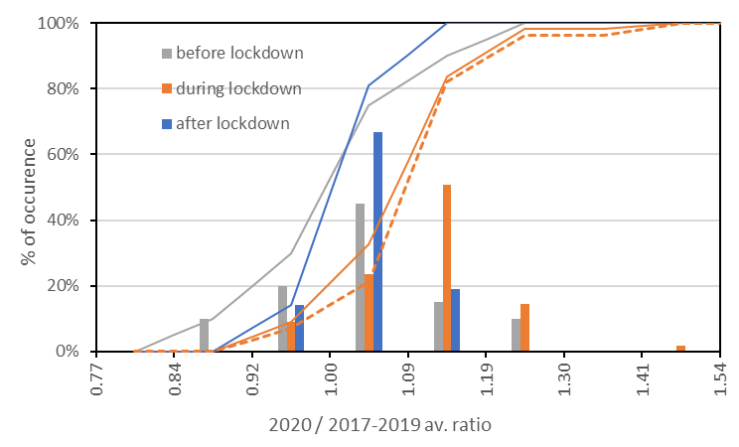

Figure S6: Occurrence frequency distributions of 2020 / 2017 - 2019 average ratios for the absorption Ångström exponent during the lockdown period, and during the 3 weeks before and after the lockdown period in Ispra. The dashed line shows the cumulative frequency of occurrence of the 2020/2017-2019 average ratio calculated for the 28 days corresponding to the eBC concentrations greater than the median during the lockdown period in 2020.

The percentage of $15-70 \mathrm{~nm}$ particle number relative to the $15-800 \mathrm{~nm}$ particle number was calculated based on hourly averaged particle number size distributions. During the period 17 Feb. - 24 May 2020, the daily average number concentration of particles with $D p$ between 15 and $800 \mathrm{~nm}$ averaged $5940 \mathrm{~cm}^{-3}$ (range 1830 and $13400 \mathrm{~cm}^{-3}$ ) in Ispra, to be compared with 6980 , 7260 , and $6660 \mathrm{~cm}^{-3}$ during the same periods in 2017, 2018, and 2019, respectively. In 2020, the fraction of sub-70nm particles 
was generally less than the 2017-2019 average during the lockdown period, and more similar to the 2017-2019 average before and after the lockdown period. This observation is better highlighted by the occurrence frequency distributions (Figure S7). Figure S7 also shows also that the days most impacted by lockdown measures were those on which total particle number concentrations were highest. On average, the sub-70 nm particle number percentage was significantly lower than expected due to lockdown measures. In comparison with both the 3 weeks before and the 3 weeks after the lockdown period, the decreases can be estimated to $-40 \%$ and $-20 \%$, respectively.

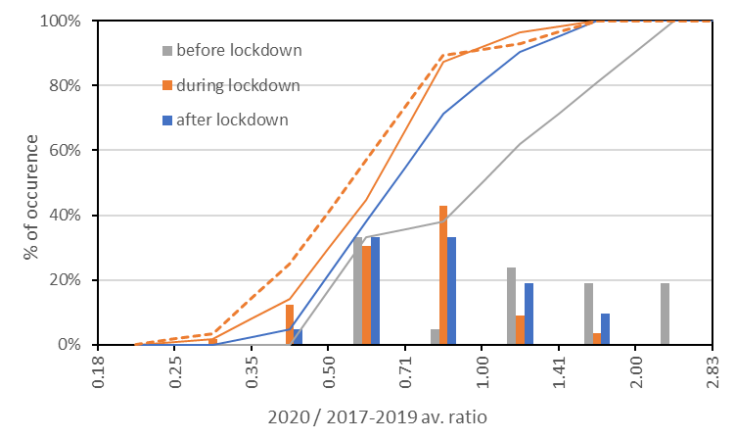

Figure S7: Same as Figure S6 for the sub-70 nm particle number percentage. Lines show cumulative frequencies of occurrence. The dashed line shows the cumulative frequency of occurrence of the 2010/2017-2019 average ratio calculated for the 28 days corresponding to the highest particle number concentrations during the lockdown period in 2020.

\section{Nitrogen oxide (NO) observed vs. expected concentrations in the Milan conurbation}

The occurrence frequency distribution of NO observed / expected concentration ratios in the Milan conurbation ( 3 urban background site average) did not show any significant decrease in NO due to the lockdown measures in comparison to the 3 weeks before the lockdown period (Figure S8, also shown in Figure 4). However, the decrease in NO was significant at the urban background site located in the city center of Milan (Figure S8). The other 2 sites of Milan are closer to highways, where traffic reduction was not as important as in the city center since e.g. heavy duty vehicles still travelled during the lockdown. In contrast, data regarding the 3 weeks following the end of the lockdown period show a significant increase of NO both in the Milan conurbation as a whole and in Milan city center (Figure S8).

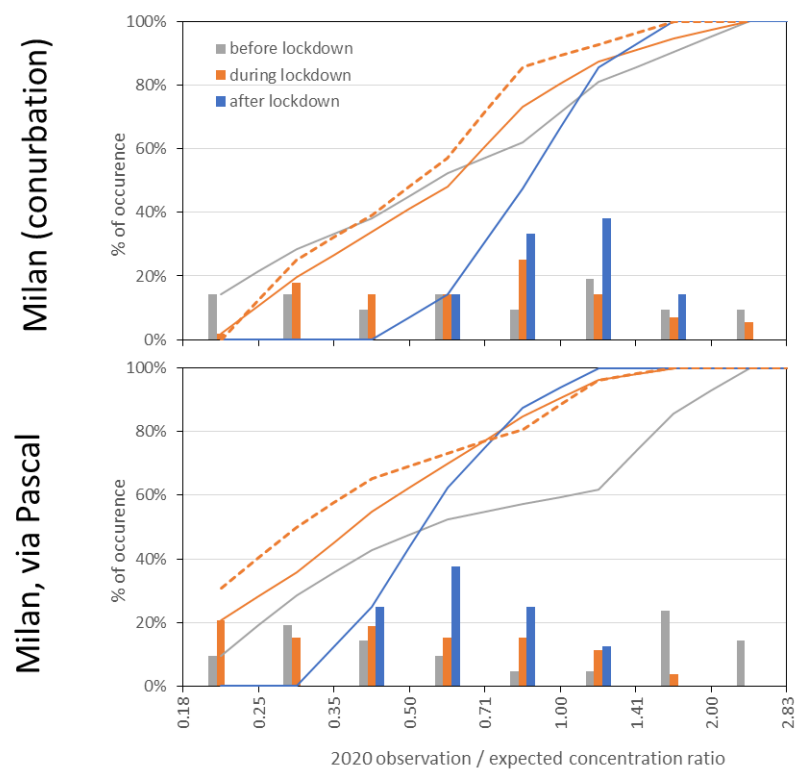

Figure S8: Occurrence frequency distributions of 2020 observed/expected concentration ratios (Obs / Exp) for NO during the lockdown period, and during the 3 weeks before and after the lockdown period in the Milan conurbation (top) and Milan city center (bottom). Lines show cumulative frequencies of occurrence. Dashed lines show the cumulative frequency of occurrence of (Obs / Exp) ratios for the 28 days corresponding to the highest (> median) CAMS forecast NO concentrations. 